\title{
Review: hospital at home is as effective as inpatient care for mortality and hospital readmissions in patients with acute exacerbations of chronic obstructive pulmonary disease
}

Ram FS, Wedzicha JA, Wright J, et al. Hospital at home for patients with acute exacerbations of chronic obstructive pulmonary disease: systematic review of evidence. BMJ 2004;329:315.

\section{Q Is hospital at home $(\mathrm{HaH})$ as effective as inpatient care for reducing mortality and readmission to hospital in patients with acute exacerbations of chronic obstructive pulmonary disease (COPD)?}

\section{METHODS}

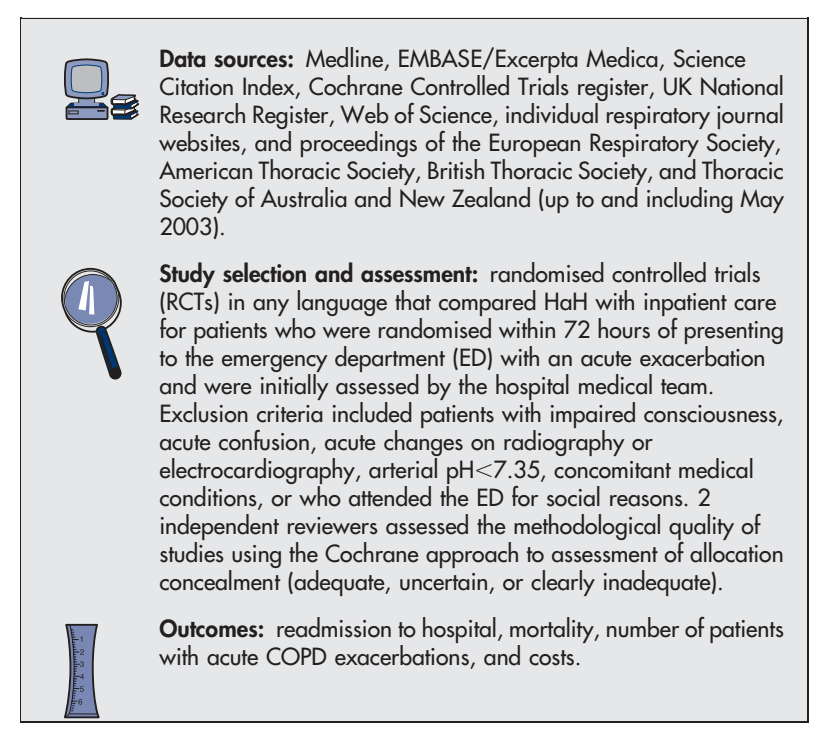

\section{MAIN RESULTS}

Of the 7 RCTs $(n=754)$ that met the selection criteria, 6 had adequate allocation concealment, and 1 had uncertain allocation concealment. HaH comprised care by a specialist nurse according to initial assessment in the ED (guided by the hospital medical team), and visits by a respiratory nurse until discharge from care. Inpatient care comprised usual treatment at the discretion of the hospital medical team.

Meta-analysis was done using a fixed effects model. The $\mathrm{HaH}$ and inpatient groups did not differ for the number of patients readmitted to hospital or for mortality (table). 4 trials reported cost analyses: 2 found that $\mathrm{HaH}$ was less expensive than inpatient care (average savings per patient $£ 536,95 \%$ CI $£ 532$ to $£ 540$ ), l found that the mean health service cost for $\mathrm{HaH}$ was approximately half of inpatient care $(£ 867 v £ 1405, \mathrm{p}=0.003)$, and 1 trial reported a savings of 201 bed days/year with $\mathrm{HaH}$ care.

\section{CONCLUSION}

In patients with acute exacerbation of chronic obstructive pulmonary disease, hospital at home does not differ from inpatient care for hospital readmissions or mortality.

For correspondence: Dr F S F Ram, National Collaborating Centre for Women and Children's Health, London, UK. fsfram@yahoo.co.uk Source of funding: no external funding.
Hospital at home $(\mathrm{HaH}) v$ inpatient care for acute exacerbations of chronic obstructive pulmonary disease*

\begin{tabular}{llllll}
\hline & \multicolumn{4}{c}{$\begin{array}{l}\text { Weighted event } \\
\text { rates }\end{array}$} \\
\cline { 3 - 4 } $\begin{array}{l}\text { Outcomes at } \\
\text { 2-3 months after } \\
\text { initial exacerbation }\end{array}$ & $\begin{array}{l}\text { Number } \\
\text { of trials }\end{array}$ & $\begin{array}{l}\text { HaH } \\
\text { care }\end{array}$ & RRR (95\% Cl) \\
\hline $\begin{array}{l}\text { Patients readmitted } \\
\text { to hospital }\end{array}$ & 7 & $28 \%$ & $31 \%$ & $11 \%(-12$ to 28) \\
Mortality & 6 & $5.3 \%$ & $8.7 \%$ & $39 \%(-5$ to 64) \\
\hline
\end{tabular}

*Abbreviations defined in glossary; RRR and Cl calculated from data in article using a fixed effects model.

\section{Commentary}

- everal investigations have compared $\mathrm{HaH}$ care with traditional hospital care. Although most studies have shown that $\mathrm{HaH}$ is as effective as inpatient care but less costly, ${ }^{12}$ the patient populations, inclusion criteria, and endpoints differed. Ram et al pooled the results of 7 studies of patients with COPD who had acute exacerbations. More recent studies reached similar conclusions. ${ }^{3} 4$

Major strengths of this review include the comprehensive search strategy that was used to identify studies and the well defined inclusion criteria. 2 independent reviewers agreed on the quality of all included RCTs.

A limitation of the findings lies in the original research. Although all of the included studies assessed $\mathrm{HaH}$ care by a specialist respiratory nurse, the frequency and length of care varied, as did ancillary services. Patients randomised to inpatient care received usual care, which varied among hospitals. This variability can make evaluation of endpoints difficult and result in flawed estimates of costs and bed-day savings.

The review by Ram et al is relevant to nurses who work in EDs, with respiratory patients, or in home health. Information about cost advantages and patient or family preferences will aid nurses in procuring optimal treatment settings for patients and help to promote early discharge from inpatient settings.

Judith L Reishtein, RN, PhD, CCRN University of Pennsylvania Philadelphia, Pennsylvania, USA

1 Coast J, Richards SH, Peters TJ, et al. Hospital at home or acute hospital care? A cost minimisation analysis. BMJ. 1998;316:1802-6.

2 Richards, SH, Coast J, Gunnell DJ, et al. Randomised controlled trial comparing effectiveness and acceptability of an early discharge, hospital at home scheme with acute hospital care. BMJ 1998;316:1796-801.

3 Hernandez C, Casas A, Escarrabill J, et al; CHRONIC project. Home hospitalisation of exacerbated chronic obstructive pulmonary disease patients. Eur Respir J 2003;21:58-67.

4 Barnett M. A nurse-led community scheme for managing patients with COPD. Prof Nurse 2003;19:93-6. 